\title{
Measles surveillance in Canada: 2018
}

\author{
Cameron Coulby' ${ }^{1}$ Francesca Reyes Domingo ${ }^{1 *}$, Joanne Hiebert ${ }^{2}$, Diane MacDonald ${ }^{1}$
}

\begin{abstract}
Background: Measles has been eliminated in Canada since 1998. Every year, the Public Health Agency of Canada presents epidemiologic evidence to the Pan American Health Organization (PAHO) to verify that measles continues to be eliminated in Canada. The objectives of this article are to: provide an epidemiologic summary of measles activity reported in 2018 in Canada, and provide documented evidence to support the continued verification of measles elimination status in Canada.

Methods: Measles surveillance data were captured by the Canadian Measles and Rubella Surveillance System (CMRSS) and descriptive analyses of demographics and risk factors were performed. Outbreak characteristics were summarized and genotypic analyses conducted. Surveillance data for 2018 were evaluated against PAHO's essential criteria for measles elimination status.
\end{abstract}

Results: In 2018, 29 measles cases were reported across five provinces in Canada, an incidence rate of 0.8 cases per $1,000,000$ population. Of these 29 cases, 16 were imported and five resulted in further transmission within Canada. The age-specific incidence rate was highest among those aged younger than one year ( 10.2 cases per $1,000,000$ population, $n=4)$. Only nine cases were considered up-to-date for measles vaccination, and 11 cases were hospitalized. Genotype information was available for most of the measles cases $(n=27)$; they were all found to be genotypes that circulated globally in 2018. Canada met or partially met three out of four of PAHO's criteria for verification of measles elimination.

Conclusion: Although importations and areas of low vaccination coverage continue to challenge Canada's elimination status, there is no evidence that endemic transmission of the measles virus has been re-established. Canada maintains its measles elimination status.
This work is licensed under a Creative Commons Attribution 4.0 International License.

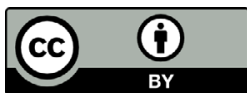

Affiliations

${ }^{1}$ Centre for Immunization and Respiratory Infectious Diseases, Public Health Agency of Canada, Ottawa, ON

${ }^{2}$ National Microbiology Laboratory, Public Health Agency of Canada, Winnipeg, MB

\section{${ }^{\star}$ Correspondence:}

phac.vpd-mev.aspc@canada.ca

Suggested citation: Coulby C, Reyes Domingo F, Hiebert J, MacDonald D. Measles surveillance in Canada: 2018. Can Commun Dis Rep 2020;46(4):77-83. https://doi.org/10.14745/ccdr.v46i04a04

Keywords: measles, travel health, surveillance, measles elimination, vaccination

\section{Introduction}

Measles, one of the most contagious human infectious diseases, was responsible for an estimated 2.6 million deaths per year before the introduction of the measles vaccine in 1963 (1). Measles has been eliminated in Canada since 1998 (2). The World Health Organization (WHO) defines elimination as the absence of endemic measles transmission for at least 12 months in a defined geographic area with a well-performing surveillance system, which includes genotyping of the virus identified in confirmed cases of measles (3).

Nevertheless, measles continues to be an important public health issue globally. In 2018, there were about 9.8 million measles cases and over 140,000 measles-related deaths worldwide (4).
This represents an increase in the global number of measles cases of over $40 \%$ and an increase in the global number of measles-related deaths of almost 30\% compared to 2017 (5). Most measles-related deaths occurred in children under five years of age (1).

As measles continues to circulate internationally, the risk of importing measles into Canada persists. The estimated first dose measles-containing vaccine coverage rate is $90 \%$ among two year olds, which is below the minimum $95 \%$ vaccination coverage for all population cohorts needed to prevent sustained measles transmission $(2,6)$. Timely and enhanced national surveillance of measles is necessary in order to rapidly detect cases and 
outbreaks and put into effect public health action that stops further transmission. Enhanced surveillance is conducted through the Canadian Measles and Rubella Surveillance System (CMRSS), which is coordinated by the Public Health Agency of Canada's (PHAC) Centre for Immunization and Respiratory Infectious Diseases and the National Microbiology Laboratory (NML). This surveillance involves weekly collection of data on confirmed measles cases (7) from all 13 provinces and territories (8).

Canada continues to be committed to measles elimination and has set vaccination coverage goals and vaccine-preventable disease reduction targets based on international standards and best practices as part of the National Immunization Strategy objectives for 2016-2021 (9). These national goals and targets are consistent with commitment to WHO disease elimination targets and the Global Vaccine Action Plan, within the Canadian context. Under the Strategy, Canada targets $95 \%$ coverage (and hence measles elimination) with one dose of the measles-mumps-rubella (MMR) vaccine by two years of age and $95 \%$ coverage with two doses of MMR by seven years of age. All the provinces and territories recommend the first dose of measles-containing vaccine at 12 months of age and the second dose between 18 months and six years of age (10). All provinces and territories, which are responsible for delivering health services including vaccination programs, have endorsed the national goals and targets.

The objectives of this surveillance report are to provide an epidemiologic summary of measles activity reported in Canada for 2018; and provide documented evidence to support the continued verification of measles elimination status in Canada.

\section{Methods}

\section{Surveillance data}

Confirmed cases of measles meeting the national case definition (7) were reported weekly to PHAC by provinces and territories through CMRSS. All confirmed cases of measles with rash onset between January 1, 2018, and December 31, 2018, were included in this report. Epidemiologic weeks of rash onset are assigned by the Centre for Immunization and Respiratory Infectious Diseases with week one ending on the first Saturday of the year. A data validation process was conducted with all provinces and territories, which included querying for missing data, identifying incorrect entries and confirming values with reporting jurisdictions. Cases with missing data were included in the analysis as appropriate. Visitors to Canada who were diagnosed with measles during their stay were included in this analysis.

\section{Genotyping}

Virus genotyping is routinely performed at NML for all confirmed cases in Canada for which viral specimens are available.

Genotyping is conducted by sequencing of specific measles genome targets in accordance with WHO guidelines $(11,12)$.
Measles viral sequences are deposited in the WHO Measles Nucleotide Surveillance (MeaNS) database and compared to designated named strains and to sequences deposited by other members of the global measles laboratory network $(12,13)$.

\section{Analysis}

Descriptive epidemiologic analyses were performed based on available fields in the CMRSS database (7). Subgroup analysis was precluded by the small number of measles cases reported in 2018.

Cases aged 1-6 years with at least one documented dose of measles-containing vaccine were classified as up-to-date in terms of measles vaccination. Those aged seven years or over and born after 1970 were classified as up-to-date for measles vaccination if they had two documented doses of measles-containing vaccine and were classified as under-vaccinated if they had only one documented dose. An adult born before 1970 was presumed to have acquired natural immunity and was considered up-to-date in terms of measles vaccination $(9,14)$. A child under one year of age was classified as up-to-date for measles vaccination status regardless of vaccination status unless the child travels outside of North America, in which case the vaccine can be given after six months of age (15).

A case was considered to be hospitalized only if admitted to hospital due to measles or due to disease complications; if only seen in the emergency department, the case was not considered hospitalized.

The source of exposure was identified by the reporting province or territory in the course of the public health investigation. The sources of exposure were classified as outside Canada (imported); within Canada and linked to an imported case (import-related); within Canada and linked to a case of unknown origin; or unknown source/sporadic.

Measles outbreaks, defined as two or more confirmed cases linked either epidemiologically, virologically or both, were described based on available information (14). Incidence rates were calculated using Statistics Canada population estimates for July 1, 2018.

\section{Results}

A total of 29 confirmed measles cases (incidence rate of 0.8 cases per $1,000,000$ population) in five provinces were reported in Canada in 2018. Of these 29 confirmed cases, 27 were genotyped. The genotypes detected were B3 $(n=7)$ and D8 $(n=20)$, both of which circulated globally in 2018 (4). Figure 1 shows the distribution of measles cases by epidemiologic week of rash onset, outbreak number, genotype and reporting province or territory. Altogether, 28 cases were laboratory-confirmed and one case was epidemiologically linked to a laboratory-confirmed case. 
Figure 1: Number of reported measles cases $(N=29)$, by epidemiologic week of rash onset, outbreak number, genotype and reporting province or territory, Canada, 2018

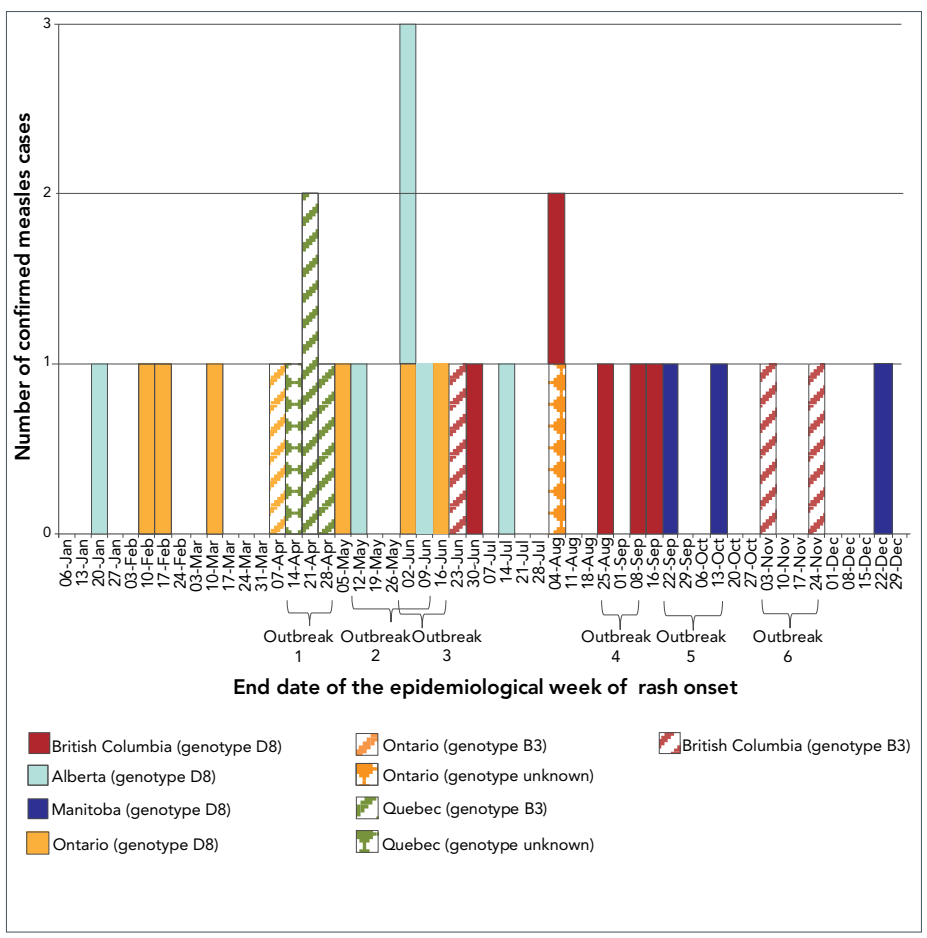

Information on age, sex and province or territory of residence was available for all measles cases reported in 2018. The cases ranged from younger than one to 53 years old, with a median age of 21 years. The most frequently reported age group was 25-44 years $(n=11)$, with the next most frequently reported aged $15-24$ years $(n=8)$. The highest incidence rate was reported in infants younger than one year of age, at 10.2 cases per $1,000,000$ population (Figure 2). Three-quarters of cases $(n=22)$ were female.

Five Canadian provinces reported measles cases in 2018: Ontario ( $n=9$, which included one visitor to Ontario); British Columbia ( $n=8)$; Alberta $(n=6)$; Quebec $(n=4)$; and Manitoba $(n=2)$. Incidence rates ranged from 0.5 to 1.6 cases per $1,000,000$ population in the provinces that reported measles cases.

\section{Vaccination}

Of the 29 measles cases reported in 2018, two-thirds $(n=20)$ were considered not up-to-date for measles vaccination for age. Of these 20 cases, 12 were documented as being not up-to-date for vaccination for age. Eight cases had unknown or missing vaccination history, but were born after 1970 and were therefore presumed not to have acquired natural immunity $(15,16)$. Of the 12 cases documented as being not up-to-date for vaccination for age, three cases were between six months and one year of age and had travelled outside of North America without receiving the first dose of measles-containing vaccine as indicated in current vaccine recommendations (15).
Figure 2: Confirmed measles cases $(\mathrm{N}=29)$ and incidence rates (per 1,000,000 population) by age group, Canada, 2018

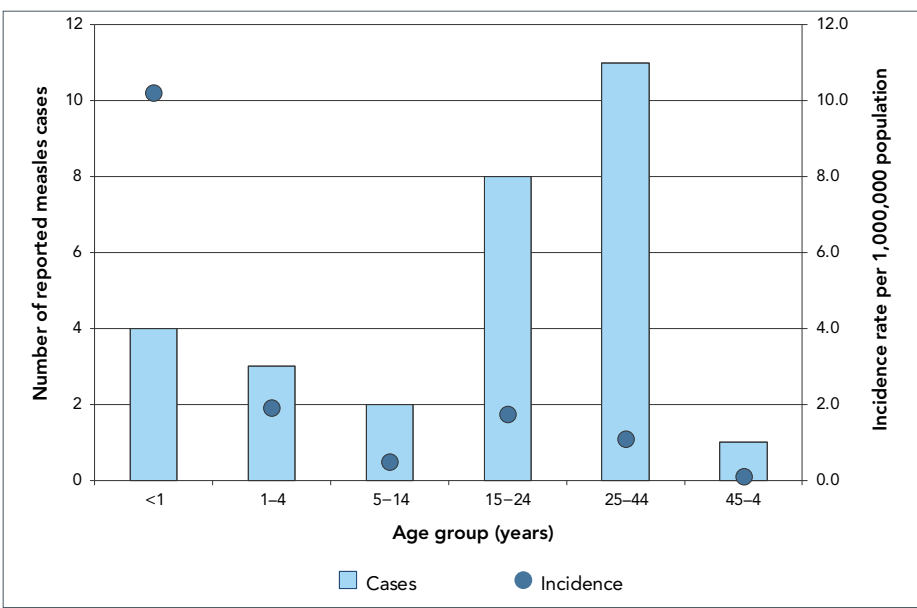

Of the 29 measles cases reported in 2018, nine were considered up-to-date for measles vaccination for age, with eight documented as having received appropriate measles vaccination for age (including one infant younger than one year of age who was unvaccinated and had not travelled outside of North America) (Figure 3). One case with unknown vaccination history had been born before 1970 (and was therefore considered up-to-date for measles immunization) and had not travelled outside of North America (15).

Figure 3: Vaccination status of confirmed measles cases (N=29), Canada, 2018

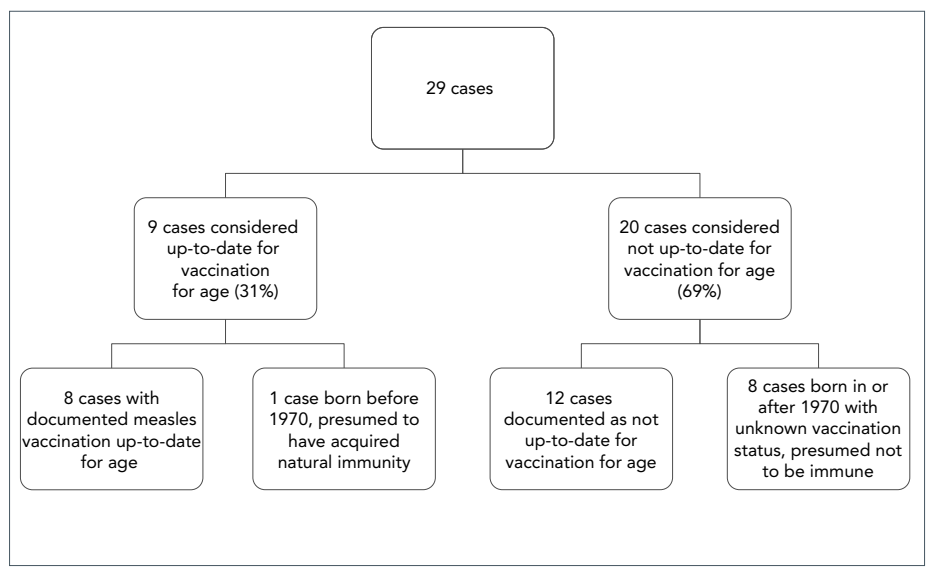

\section{Hospitalization}

Of the 29 cases reported in 2018, 24 had hospitalization information. In total, 11 cases were hospitalized, a measles-specific hospitalization rate of 0.3 per $1,000,000$ population. The median age of hospitalized cases was 15 years (range: 4-51 years). Of the 11 hospitalized cases, eight had vaccination information available. Of these eight cases, six had no documented doses of measles-containing vaccine but two were considered fully vaccinated. 


\section{Sources of exposure}

Of the 29 confirmed cases of measles in 2018, 16 were imported into Canada after exposure to measles during travel to the following countries or regions: India $(n=7)$; Ukraine $(n=4)$; Brazil $(n=1)$; the Philippines $(n=1)$; Romania $(n=1)$; Southeast Asia (not including India, $n=1)$; and Uganda $(n=1)$. Fourteen of the imported cases were genotyped, and the genotypes were consistent with those known to be endemic in the source country or reported to the WHO MeaNS database as detected in the source country (13).

Of the 16 imported cases, five transmitted the disease within Canada, resulting in a further seven import-related cases. In total, imported and import-related cases accounted for three-quarters $(n=23)$ of cases in 2018. Of the cases that were neither imported nor import-related $(n=6)$, four had no recent history of travel or known links to other confirmed measles cases, one was exposed in Canada to a case of unknown origin and one cannot be assigned as imported or non-imported because the exposure period occurred both in another country with known measles activity and within Canada. All six of these remaining cases were genotyped and the genotypes were D8 $(n=5)$ and B3 $(n=1)$, both of which were circulating globally.

\section{Outbreaks}

Six measles outbreaks were identified in Canada in 2018 (details are provided in Table 1). All outbreaks were small (2-4 cases per outbreak) and transmission was limited to household contacts or other close contacts of the index case. No outbreak went beyond the second generation. For all outbreaks combined, the median time interval between the rash onsets of the index case and the secondary cases was 13 days, with a range of 9 to 27 days. Only one case had an incubation period that was outside the expected range of 7 to 21 days; this case had received immune globulin shortly after exposure, which may have delayed but not prevented disease onset. Of the 29 cases reported in 2018, 14 were outbreak-related.

Table 1: Summary of measles outbreaks in Canada $(\mathrm{N}=6)$, by earliest date of rash onset, 2018

\begin{tabular}{|c|c|c|c|c|c|}
\hline $\begin{array}{c}\text { Outbreak } \\
\text { number }\end{array}$ & $\begin{array}{c}\text { Province/ } \\
\text { territory }\end{array}$ & $\begin{array}{l}\text { Number } \\
\text { of cases }\end{array}$ & $\begin{array}{l}\text { End date of } \\
\text { epidemiologic } \\
\text { week of rash } \\
\text { onset of index } \\
\text { case }\end{array}$ & $\begin{array}{c}\text { Genotype } \\
\text { (Strain) }^{a}\end{array}$ & Description \\
\hline 1 & Quebec & 4 & April 15 & $\begin{array}{l}\text { B3 (MVs/ } \\
\text { Dublin. } \\
\text { IRL/8.16/) }\end{array}$ & $\begin{array}{l}\text { The index case reported travel to Romania during the exposure period. } \\
\text { Three secondary cases among family contacts of the index case were } \\
\text { subsequently reported. All of the cases were unvaccinated. }\end{array}$ \\
\hline 2 & Alberta & 2 & May 13 & D8 & $\begin{array}{l}\text { The index case reported travel to India during the exposure } \\
\text { period. One secondary case, a close contact of the index case, was } \\
\text { subsequently reported. The vaccination history of the index case was } \\
\text { unknown. The secondary case was unvaccinated. }\end{array}$ \\
\hline 3 & Ontario & 2 & June 3 & $\begin{array}{l}\text { D8 (MVs/ } \\
\text { Gir Somnath. } \\
\text { IND/42.16/) }\end{array}$ & $\begin{array}{l}\text { The index case reported travel to Ukraine during the exposure } \\
\text { period. One secondary case, a close contact of the index case, was } \\
\text { subsequently reported. The vaccination history of the index case was } \\
\text { unknown. The secondary case was unvaccinated. }\end{array}$ \\
\hline 4 & $\begin{array}{l}\text { British } \\
\text { Columbia }\end{array}$ & 2 & August 26 & $\begin{array}{l}\text { D8 (MVs/ } \\
\text { Osaka. } \\
\text { JPN/29.15/) }\end{array}$ & $\begin{array}{l}\text { The index case did not report travel outside of Canada during the } \\
\text { exposure period, but was potentially exposed to an international } \\
\text { measles case at a Canadian port. One secondary case, a contact of } \\
\text { the index case, was subsequently reported. Both cases were fully } \\
\text { vaccinated. }\end{array}$ \\
\hline 5 & Manitoba & 2 & September 9 & $\begin{array}{l}\text { D8 (MVs/ } \\
\text { Samut Sakhon. } \\
\text { THA/49.16) }\end{array}$ & $\begin{array}{l}\text { The index case reported travel to Southeast Asia during the exposure } \\
\text { period. One secondary case, a close contact of the index case, } \\
\text { was subsequently reported. The index case was unvaccinated. The } \\
\text { secondary case was fully vaccinated. }\end{array}$ \\
\hline 6 & $\begin{array}{l}\text { British } \\
\text { Columbia }\end{array}$ & 2 & November 4 & B3 & $\begin{array}{l}\text { The index case reported travel to the Philippines. One secondary } \\
\text { case, a contact of the index case, was subsequently reported. The } \\
\text { vaccination history of the index case was unknown. The secondary case } \\
\text { was fully vaccinated. }\end{array}$ \\
\hline
\end{tabular}

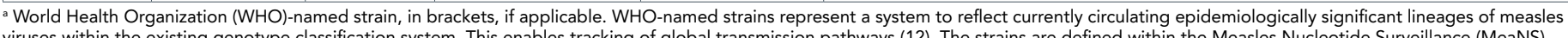

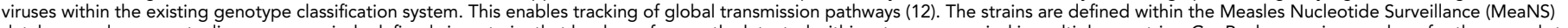

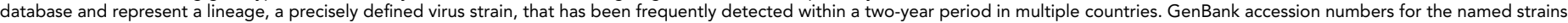
are KY013331, KY120864, LC072667 and MK079566 


\section{Discussion}

\section{Epidemiology of measles in Canada, 2018}

In 2018, 29 confirmed cases of measles were reported in Canada. This is below the median number of cases reported since the beginning of enhanced surveillance in 1998 (median of 35 cases per year). This decrease in the number of cases was in contrast to a trend of increasing rates of measles globally. In the United States, the number of measles cases and outbreaks in 2018 increased compared to $2017(5,17)$. Of the 16 measles cases imported into Canada in 2018, only five resulted in secondary transmission, demonstrating that sustained transmission was not observed.

Imported and import-related cases accounted for the large majority of measles cases in 2018, underscoring the ongoing risk that international travel places on the spread of measles in Canada. This was reflected by the genotype data of the cases that identified the two main genotypes, B3 and D8, both of which were circulating globally in 2018. These genotypes were also circulating globally in 2017 and were detected in Canada (18). However, the genotypes capture genetically related sequences, and multiple strains are contained within the genotypes. For measles molecular epidemiology, strains are informative. The strains detected in 2017, with the exception of the genotype B3 named strain MVs/Dublin.IRL/8.16/, were not detected in 2018.

Over two-thirds of the measles cases reported in 2018 were not up-to-date for measles vaccination for age. This highlights the importance of adhering to vaccine recommendations. The seven cases of breakthrough disease that developed measles despite being fully vaccinated may have failed to develop an appropriate immune response. Alternatively, vaccine-induced immunity may have waned to non-protective levels or the vaccine was stored, handled or administered improperly $(19,20)$. Two of these seven cases had documented doses of measles vaccination outside of Canada, where vaccine storage and administration guidelines may be different.

Over one-third (11/29) of the cases required hospitalization, supporting previously published evidence that measles infection can lead to serious illness (1).

\section{Verification of measles elimination through national and international goals and targets}

The Pan American Health Organization (PAHO) set out four criteria for the ongoing verification of measles elimination (21). Canada met or partially met three of the four criteria in 2018 (Table 2). Since the criteria are based on investigation of measles-like illnesses (i.e. suspected cases), whereas only confirmed cases are nationally notifiable in Canada, the data presented in this article can only indirectly address the PAHO criteria. Canada's national surveillance system for measles performs well, being able to detect imported and import-related cases, as well as cases with unknown sources of exposure. By ensuring measles elimination according to internationally accepted criteria, Canada also meets its established national goals and targets.

\section{Table 2: Pan American Health Organization essential criteria for the verification of measles elimination}

\begin{tabular}{|l|l|l|}
\multicolumn{1}{|c|}{ Criterion } & \multicolumn{1}{|c|}{ Indicator } & \multicolumn{1}{|c|}{ Description } \\
\hline $\begin{array}{l}\text { Verify the interruption } \\
\text { of endemic measles } \\
\text { cases for a period of } \\
\text { at least three years } \\
\text { from the last known } \\
\text { endemic case, in the } \\
\text { presence of high- } \\
\text { quality surveillance. }\end{array}$ & $\begin{array}{l}\text { Zero cases } \\
\text { of endemic } \\
\text { transmission. }\end{array}$ & $\begin{array}{l}\text { Criterion met. } \\
\text { Canada achieved measles } \\
\text { elimination status in 1998. } \\
\text { Since then, molecular and } \\
\text { epidemiologic data continue } \\
\text { to demonstrate that no } \\
\text { viral strain has circulated } \\
\text { for a period of } \geq 1 \text { year } \\
\text { (3,18,21,22). }\end{array}$ \\
\hline $\begin{array}{l}\text { Maintain high-quality } \\
\text { surveillance, sensitive } \\
\text { enough to detect } \\
\text { imported and import- } \\
\text { related cases. }\end{array}$ & $\begin{array}{l}>2 \text { suspect } \\
\text { cases per } \\
100,000 \\
\text { population } \\
\text { adequately } \\
\text { investigated. }\end{array}$ & $\begin{array}{l}\text { Criterion partially met. } \\
\text { CMRSS allows the } \\
\text { identification of imported } \\
\text { and import-related cases } \\
\text { that are confirmed to meet } \\
\text { the case definition, but not } \\
\text { suspected cases. }\end{array}$ \\
\hline $\begin{array}{l}\text { Verify the absence of } \\
\text { endemic measles virus } \\
\text { strains through viral } \\
\text { surveillance. }\end{array}$ & $\begin{array}{l}\text { Measles } \\
\text { genotype } \\
\text { assessed } \\
\text { in } 80 \% \text { of } \\
\text { outbreaks. }\end{array}$ & $\begin{array}{l}\text { Criterion met. } \\
\text { Genotype information } \\
\text { was available for 6/6 of } \\
\text { outbreaks reported in 2018. } \\
\text { Genotype information was } \\
\text { also available for 100\% of } \\
\text { sporadic (non-outbreak } \\
\text { related) measles cases. }\end{array}$ \\
\hline $\begin{array}{l}\text { Verify adequate } \\
\text { immunization in the } \\
\text { population. }\end{array}$ & $\begin{array}{l}\text { Criterion not met. } \\
\text { population } \\
\text { cohorts aged } \\
1-40 \text { years } \\
\text { have received } \\
\text { a measles- } \\
\text { containing } \\
\text { vaccine. }\end{array}$ & $\begin{array}{l}\text { Canada currently measures } \\
\text { (biennially) measles } \\
\text { vaccination coverage rates at } \\
\text { two and seven years of age, } \\
\text { and therefore is unable to } \\
\text { assess measles vaccination } \\
\text { coverage for all ages 1-40 } \\
\text { years. The 2017 childhood } \\
\text { National Immunization } \\
\text { Coverage Survey estimated } \\
\text { first dose measles-containing } \\
\text { vaccine coverage in two year } \\
\text { olds to be 90\% (6). }\end{array}$ \\
\hline
\end{tabular}

Abbreviation: CMRSS, Canadian Measles and Rubella Surveillance System

Canada falls short on the criterion regarding measles-containing vaccine coverage. Canada currently measures (biennially) measles vaccination coverage rates at 2 and 7 years of age, and therefore is unable to assess measles vaccination coverage for all ages between 1 and 40 years, as set out in the PAHO elimination framework. The 2017 estimate for two year olds receiving measles-containing vaccine is $90 \%$, below the $\mathrm{PAHO}$ indicator of $95 \%$ (6). This estimate is derived from a survey that collected data from parent-held vaccination records, in which some information may be incomplete, erroneous or missing altogether. As vaccine doses with missing or invalid date are not counted in the calculation of coverage, the survey most likely underestimates coverage. 


\section{Limitations}

Only measles cases that interact with the Canadian health system are captured in enhanced measles surveillance, and therefore visitors to Canada who do not seek healthcare may not be detected. However, most chains of transmission did result from known imported cases in 2018.

Information on mortality and detailed information on morbidity (e.g. length of hospitalization, sequelae) are not currently captured by CMRSS, limiting the ability to completely describe the burden of illness due to measles.

\section{Conclusion}

Both in Canada and abroad, maintaining high vaccination coverage rate with measles-containing vaccine requires a sustained public health effort and is an essential component of a strategy for achieving and maintaining measles elimination. Although importation of measles and areas of low vaccination coverage continue to challenge Canada's elimination status, there is no evidence that endemic transmission of the measles virus has been re-established. This is supported by high overall vaccination coverage rates, the small number of secondary cases that resulted from imported cases and the available laboratory information that indicates that cases resulted from measles strains circulating internationally in 2018 .

\section{Authors' statement}

CC - Methodology, software, formal analysis, investigation, data curation, writing-original draft, writing-review and editing, visualization

FRD - Conceptualization, methodology, formal analysis, writing-original draft, writing-review and editing, project administration

$\mathrm{JH}$ - Methodology, validation, investigation, data curation, writing-original draft, writing-review and editing DM - Conceptualization, methodology, writing-review and editing, project administration

\section{Conflict of interest}

None.

\section{Acknowledgements}

The authors gratefully acknowledge the continued cooperation and efforts of provincial and territorial surveillance and laboratory partners for providing and validating data captured by the Canadian Measles and Rubella Surveillance System (CMRSS), for referring specimens for molecular surveillance (genotyping) and for their review of the report content.

\section{Funding}

This work was supported by the Public Health Agency of Canada.

\section{References}

1. World Health Organization (WHO). Measles Geneva $(\mathrm{CH})$ : WHO. http://www.who.int/news-room/fact-sheets/detail/ measles

2. King A, Varughese P, De Serres G, Tipples GA, Waters J; Working Group on Measles Elimination. Measles elimination in Canada. J Infect Dis 2004 May;189 Suppl 1:S236-42. DOI PubMed

3. Elimination of measles rubella and congenital rubella syndrome in Canada documentation and verification report: Executive Summary. Ottawa (ON): Government of Canada. https://www.canada.ca/en/public-health/ services/immunization/vaccine-preventable-diseases/ elimination-measles-rubella-congenital-rubella-syndrom e-canada-documentation-verification-report.html

4. Patel MK, Dumolard L, Nedelec Y, Sodha SV, Steulet C, Gacic-Dobo M, Kretsinger K, McFarland J, Rota PA, Goodson JL. Progress toward regional measles eliminationworldwide, 2000-2018. MMWR Morb Mortal Wkly Rep 2019 Dec;68(48):1105-11. DOl PubMed

5. Dabbagh A, Laws RL, Steulet C, Dumolard L, Mulders MN, Kretsinger K, Alexander JP, Rota PA, Goodson JL. Progress toward regional measles elimination - worldwide, 20002017. MMWR Morb Mortal Wkly Rep 2018 Nov;67(47):13239. DOI PubMed

6. Highlights from the. 2017 childhood National Immunization Coverage Survey (cNICS). Ottawa (ON): Government of Canada. https://www.canada.ca/en/services/health/ publications/vaccines-immunization/vaccine-uptak e-canadian-children-preliminary-results-2017-childhood-nat ional-immunization-coverage-survey.html

7. Public Health Agency of Canada. Case definitions for diseases under national surveillance: results of provincial/ territorial $(\mathrm{P} / \mathrm{T})$ consultation process. Can Commun Dis Rep 2009;35-Suppl 2:71-2. https://www.canada.ca/ content/dam/phac-aspc/migration/phac-aspc/publicat/ ccdr-rmtc/09pdf/35s2-eng.pdf

8. Canadian measles/rubella surveillance system. Ottawa (ON): Government of Canada. https://www.canada.ca/en/ public-health/services/surveillance.html\#a5

9. Canadian vaccination coverage goals and vaccine preventable disease reduction targets by 2025: Vaccine preventable disease reduction targets by 2025: Diseases under elimination: Maintain elimination status. Ottawa (ON): Government of Canada. https://www.canada. $\mathrm{ca} /$ en/public-health/services/immunization-vaccinepriorities/national-immunization-strategy/ vaccination-coverage-goals-vaccine-preventable-disea ses-reduction-targets-2025.html\#2.1

10. Provincial and territorial routine and catch-up vaccination schedule for infants and children in Canada. Ottawa (ON): Government of Canada; 2018. https://www. canada.ca/en/public-health/services/provincial-territoria I-immunization-information/provincial-territoria |-routine-vaccination-programs-infants-children.html 
11. World Health Organization. Expanded Programme on Immunization (EPI). Standardization of the nomenclature for describing the genetic characteristics of wild-type measles viruses. Wkly Epidemiol Rec 1998 Aug;73(35):265-9. https://apps.who.int/iris/bitstream/handle/10665/230557/ WER7335_265-269.PDF?sequence=1\&isAllowed=y PubMed

12. World Health Organization. Genetic diversity of wild-type measles viruses and the global measles nucleotide surveillance database (MeaNS). Wkly Epidemiol Rec 2015 Jul;90(30):373-80. https://apps.who.int/iris/ bitstream/handle/10665/242393/WER9030_373-380. PDF? sequence=1\&isAllowed=y PubMed

13. Rota PA, Brown K, Mankertz A, Santibanez S, Shulga S, Muller CP, Hübschen JM, Siqueira M, Beirnes J, Ahmed H, Triki H, Al-Busaidy S, Dosseh A, Byabamazima C, Smit S, Akoua-Koffi C, Bwogi J, Bukenya H, Wairagkar N, Ramamurty N, Incomserb P, Pattamadilok S, Jee $Y$, Lim W, Xu W, Komase K, Takeda M, Tran T, Castillo-Solorzano C, Chenoweth P, Brown D, Mulders MN, Bellini WJ, Featherstone D. Global distribution of measles genotypes and measles molecular epidemiology. J Infect Dis 2011 Jul;204 Suppl 1:S514-23. DOI PubMed

14. Measles and Rubella Elimination Working Group (MREWG), Health Canada, Public Health Agency of Canada. Guidelines for the prevention and control of measles outbreaks in Canada: An Advisory Committee Statement (ACS) Measles and Rubella Elimination Working Group (MREWG). Can Commun Dis Rep 2013;39(ACS-3):1-52. DOI

15. Measles vaccine: Canadian immunization guide: Table 1: Criteria for measles immunity. Ottawa (ON): Government of Canada; 2018. https://www.canada.ca/ en/public-health/services/publications/healthy-living/ canadian-immunization-guide-part-4-active-vaccines/page12-measles-vaccine.html\#p4c11t1
16. Immunization of travellers: Canadian immunization guide. Ottawa (ON): Government of Canada; 2017. https:// www.canada.ca/en/public-health/services/publications/ healthy-living/canadian-immunization-guide-part3-vaccination-specific-populations/page-

9-immunization-travellers.html

17. The United States Centre for Disease Control and Prevention. Measles (Rubeola): measles cases and outbreaks. Atlanta (GA): U.S. Department of Health \& Human Services; 2019. https://www.cdc.gov/measles/cases-outbreaks.html

18. Public Health Agency of Canada. Measles surveillance in Canada: 2017. Ottawa (ON): Government of Canada; 2018. https://www.canada.ca/en/public-health/services/ publications/diseases-conditions/measles-surveillancecanada-2017.html

19. Breakwell L, Moturi E, Helgenberger L, Gopalani SV, Hales C, Lam E, Sharapov U, Larzelere M, Johnson E, Masao C, Setik E, Barrow L, Dolan S, Chen TH, Patel M, Rota P, Hickman C, Bellini W, Seward J, Wallace G, Papania M. Measles outbreak associated with vaccine failure in adults - Federated States of Micronesia, February-August 2014. MMWR Morb Mortal Wkly Rep 2015 Oct;64(38):1088-92. DOI PubMed

20. Hinman AR, Orenstein WA, Mortimer EA Jr. When, where, and how do immunizations fail? Ann Epidemiol 1992 Nov;2(6):805-12. DOl PubMed

21. Pan-American Health Organization. Plan of action. Documentation and verification of measles, rubella and congenital rubella syndrome elimination in the region of the Americas. Washington (DC): PAHO; 2010. 